\title{
Social representations and resident attitudes: A multiple-mixed-method approach
}

\author{
Philipp Wassler \\ Department of Tourism and Hospitality, Bournemouth University, United Kingdom \\ Thi Hong Hai Nguyen \\ Department of Marketing, Events \& Tourism, University of Greenwich, United Kingdom \\ Le Quyen Mai \\ Department of Political and Cultural Change, Center for Development Research, University of Bonn, Germany \\ Markus Schuckert \\ School of Hotel and Tourism Management, The Hong Kong Polytechnic University, Hong Kong, SAR, China
}

\begin{abstract}
Resident attitudes towards tourism are well researched, but related approaches vary. Social Representations (SR), a set of ideas, values, knowledge and explanations forming the social reality of a community, are one of the most misunderstood concepts in regard. This study demonstrates a practical way to identify, characterize and understand SR through a proposed multiple-mixed-method approach, taking the case of Vietnamese residents' attitude towards Chinese tourism in Vietnam. Cluster analysis, member-checking interviews and expert interviews are combined for this purpose. Findings show that attitude clusters within the study population are heavily intertwined with relevant SR of Chinese tourism. The method offered permits a contextual understanding of SR, providing a better comprehension of historical and socio-political factors for resident studies. It is thus hoped that the proposed method opens the door for a better understanding of the social psychology of residents, but also of other stakeholders and groups of interest.
\end{abstract}

Keywords: social representations; resident attitudes; Vietnam; multiple-mixed-method; Chinese tourism

\section{INTRODUCTION}

The attitudes of residents toward tourism and related development have long been of interest, as planners have striven to understand public opinions in order to gain support for tourism initiatives (Harrill, 2004). However, the literature shows a wide range of approaches and a persistent conceptual ambiguity in terms of scientific perspective, conceptualization and contextual factors (Chen \& Raab, 2012; Eusébio, Vieira, \& Lima, 2018; Woosnam, 2012).

Much extant research assumes that residents are largely aware of possible negative and positive impacts of tourism (Ap, 1992; Andereck, Valentine, Knopf \& Vogt, 2005; Sharpley, 2014; 2018). This notion lies at the heart of Social Exchange Theory (SET) (Sharpley, 2018), arguably the most widely used theoretical underpinning for tourism host attitude studies. SET predicts that residents would show less support for tourism if they were to perceive the negative impacts/costs of tourism to outweigh positive impacts/benefits (Ap, 1992; Kim, Jun, Walker, \& Drane, 2015; Sharpley, 2014; Ward \& Berno, 2011). This assumption, however, has several shortcomings: people are not necessarily linear-rational information processors; individual knowledge is often socially derived rather than experience-based; and perceptions are formed within a wider socio-cultural and historical framework (Pearce, Moscardo \& Ross, 1996). Sharpley (2014) points out that many residents also do not directly interact with tourists; so that their attitudes tend to be based on factors other than direct experience (Woosnam, 2012). In addition, SET largely focuses on individual perceptions rather than individual-community interactions in forming beliefs. This wider, context-based picture is well addressed using Social Representations Theory (SRT).

Social Representations (SR) are influences within society that determine how people 
negotiate their daily lives and are usually expressed in a set of ideas, values, knowledge and explanations that form the social reality of a community (Pearce et al., 1996). As such, they are not fixed but dynamic; operate at different levels of society; and are determined by various sources, including personal experience and the media (Fredline \& Faulkner, 2000; Höijer, 2011). Moscardo (2011) furthermore notes that SRT links individuals' attitudes to their relevant social context; recognizes the importance of power; and understands the link between knowledge (e.g. of tourism) and control over related decisions. SR relating to residents' attitudes towards tourism are also likely to be complex in nature and to happen at different levels.

As such, SRT can be positioned as a backdrop to existing SE frameworks rather than as being opposed to them. In fact, Serge Moscovici (1976), Romanian-French social psychologist and father of SRT, had conceptualized SR as a code for SE through classifying and naming various aspect of social reality. On the same line, recent studies have shown that residents' form their attitude towards tourism based on a wide range of scarcely explored factors, ranging from emotional solidarity between host and guest (e.g. Woosnam \& Norman, 2010; Woosnam \& Aleshinloye, 2018) to wider contextual issues, such as governance, politics and history (e.g. Wassler, Schuckert, Hung, \& Petrick, 2018).

In addition to a merely descriptive approach towards resident attitudes, SR offer thus the potential to investigate a contextualized undercurrent to what is known about residents' attitude formation. This is not only of theoretical use, but also aids destination governance in times where manipulation of the public has become relatively easy through the use of social media and other alternative news sources (Fedeli, 2019).

However, methods for empirically applying SRT are fragmented and have been described as both, malleable and confusing (Wagner, Duveen, \& Farr, 1999; Sharpley, 2014; Voelklein \& Howarth, 2005). Particularly in a tourism context, studies range from SR in the context of stakeholder analysis (Moscardo, 2011) to the management of tourist selfies (Pearce \& Moscardo, 2015) and are often lacking theoretical depth (Aquino \& Andereck, 2018). Furthermore, methods to approach SR are equally fragmented, ranging anywhere from cluster analysis (Andriotis \& Vaughan, 2003; Fredline \& Faulkner, 2000) and semiotic analysis (Moscardo, 2011) to qualitative or mixed-methods (e.g. Aquino \& Andereck, 2018; Dickinson \& Robbins, 2008). Additionally, findings are often descriptive and lack a deeper explanation of the SR identified (Sharpley, 2014).

In order to shed light on this ambiguity, the present study is based on Vietnamese resident attitudes towards inbound tourism from the People's Republic of China (henceforth China). Chinese tourists numbered 4 million, almost one third of all visitors to the country in 2017, having grown rapidly from 1.9 million in 2014 (VNAT, 2018). Despite the magnitude and value of this market, the relationship between Chinese tourists and Vietnamese hosts has been turbulent in recent years; assumingly due to recent unresolved territorial disputes and larger political conflicts. This has led to an array of practical confrontations. For instance, Chinese tourists have been refused service in hotels and restaurants in several cities (Dan Tri, 2014; Giao Duc Viet Nam, 2014; Zing.vn, 2016). In addition, Chinese tourists wearing sweaters with maps of China's claims on maritime territory have led to tourists being treated rudely or fully refusing them entry to the country (South China Morning Post, 2018). On a broader line, Nguyen and Nguyen (2018) claim that $74 \%$ of the Vietnamese population have negative opinions about China as a political entity.

Nonetheless, Vietnamese residents' perceptions of Chinese tourism are unresearched and the above discussion suggests they are embedded in a more complex socio-political context. SRT is thus likely to be a suitable theoretical basis to amend this research gap and the present 
study seeks to develop and demonstrate a workable method supporting this theoretical base.

As a result, the goal of this study is to take the case of Vietnamese residents' attitude towards Chinese tourism in order to propose a multiple-mixed-method approach for identifying and understanding underlying SR; allowing finally to comprehend and classify them according to relevant theory. A three-stage multiple-mixed-method is offered for this purpose, which combines cluster analysis, member-checking interviews and discussions with experts. Findings are hoped to not only offer a method applicable for further studies, but also a deeper practical understanding on the complex relationship among Vietnam and China.

\section{LITERATURE REVIEW}

\section{Understanding residents ' attitude towards tourism}

Although approaches to resident studies in tourism vary, common denominators can be summarized as: reliance on anthropological and psychological perspectives; an assumption that communities are heterogeneous and may show varying levels of tourism support; and socio-cultural impacts deriving from the tourism-resident relationship (Mason \& Cheyne, 2000). Communal approaches have furthermore largely focused upon variables influencing residents' perceptions of tourism and segmentation studies (Sharpley, 2014).

Studies have succeeded in identifying a wide range of those variables influencing residents' attitudes. These include extrinsic variables, such as the level and density of tourism development, the type of tourism, seasonality of the destination, and the level of national development. Intrinsic variables, on the other hand, include economic/employment dependency on tourism, community attachment, distance from the tourism zones, interaction with tourists, personal values, social identity/status and demographics. Harrill (2004) summarizes related variables in an extensive review and identifies the most salient. Socioeconomic variables such as age, gender, income and length of residence have additionally been linked to resident attitudes, but with mixed and contradictory results (Mason \& Cheyne, 2000; Perdue, Long \& Allen, 1990).

Spatial variables assume that the closer residents live to tourism activities, the more negative their attitude will be (Harrill, 2004). Related studies include geographical proximity (Belisle \& Hory, 1980; Bourgham \& Butler, 1981; Harrill \& Potts, 2003); use of recreational areas (Gursoy, Jurowsky \& Uysal, 2002); and location of residential areas (Wassler et al., 2018). Findings here have also been contradictory, with studies showing that residents living closer to tourism centers may have less favorable attitudes (Harrill \& Potts, 2003), more favorable attitudes (Belisle \& Hoy,1980), or may show no difference in attitude at all (Wassler et al., 2018).

Economic variables are perhaps the most consistent factors in related literature, since residents who benefit financially from tourism often tend to be more in favor of it (Williams \& Lawson, 2001). Economic dependency is thus known to, at least in parts, influence residents' attitudes towards tourism development (Jurowski, Uysal, \& Williams, 1997; McGehee \& Andereck, 2004). Harrill (2004) however points out that this relationship is far from simple; since residents may seek to enjoy the economic benefits, while minimizing sociocultural impacts (Evans-Pritchard, 1989). Alternatively, they may equate economic benefits from tourism with dis-benefits such as increased cost of living (Cooke, 1982). In some cases, residents who are directly involved in the tourism business were also found to show more negative attitudes than others (Haukeland, 1984).

Another stream of research connects the relationship between residents and tourists to residents' attitudes about tourism. Emotional solidarity has been introduced recently to examine communalities between host and guest (e.g. Hasani, Moghavvemi, \& Hamzah, 2016; 
Woosnam, 2012; Woosnam \& Aleshinloye, 2018; Woosnam \& Norman, 2010; /2). According to Jacobs and Allen (2005), this concept refers to a feeling which binds individuals or groups together rather than separating them, creating a connection rather than friction. Emotional solidarity has been successfully related to residents' attitudes through a distinct set of variables; among which are welcoming nature, emotional closeness, and sympathetic understanding (e.g. Hasani et al., 2016; Woosnam, 2012). A different approach has looked at antecedents of residents' emotional solidarity, where shared beliefs, shared behavior and interaction have been predominant concepts (Woosnam \& Aleshinloye, 2018).

The contradictory nature of many of these findings is thought to stem from variety of reasons; among the most salient being the treatment of residents as a homogeneous population, rather than a mixture of different attitude segments (Andriotis \& Vaughan, 2003; Sharpley, 2014). Hence, several studies have sought to segment resident attitudes based on cluster analysis, taking a heterogeneity of relevant subgroups into account (Presenza \& Sheehan, 2013).

In a seminal study, Davis, Allen and Cosenza (1988) identified five clusters of Florida residents with increasingly positive attitudes towards tourists: "haters", "cautious romantics", "in-betweeners", "love "em for a reason", and "lovers". Subsequently, researchers have found resident clusters ranging in attitude from very negative to very positive (Aguilo Pérez \& Rosselló Nadal, 2005; Andriotis \& Vaughan, 2003; Brida, Osti \& Barquet, 2010; Evans, 1993; Fredline \& Faulkner, 2000; 2001; Madrigal, 1995; Ryan \& Montgomery, 1994; Small, 2007; Wassler et al., 2018; Williams \& Lawson, 2001; Zhou \& Ap, 2009; Zhou, 2010). Although there are notable differences in cluster denominations and the strength of empirical evidence, communalities among the most extreme clusters are common (Fredline \& Faulkner, 2000). Furthermore, the most positively motivated cluster usually regards the economic benefits of tourism to be of the highest importance, while the most negative highlight its negative social and environmental impacts (Andriotis \& Vaughan, 2003).

Finally, a few studies have attempted to link clusters to determinate variables. For instance, Aguilo Pérez and Rosselló Nadal (2005) analyzed their resident clusters in terms of income level and place of residence, while Andriotis and Vaughan (2003) found increasingly positive attitudes with increasing levels of education. Sharpley (2014, p.44) however, notes a persistent weakness in such studies, which "describe clusters, and ... describe variables that define those clusters, yet ... are unable to explain why the members of clusters collectively ascribe to particular perceptions of tourism". This gap is partly bridged by a recent study of Wassler et al. (2018), who attempt to identify Hong Kong residents' collective beliefs by combining cluster analysis with semi-structured "member-checking" interviews.

Nevertheless, models explaining residents' attitude towards tourism remain largely simplistic (Zhang, Inbarakan, \& Jackson, 2006) and lack theoretical support (Ap, 1990; Liu \& Var, 1986). Extant studies are typically based on SE principles alone and a deep theoretical understanding in the field, particularly of contextual factors, is lacking (Sharpley, 2014).

\section{Social Representations Theory in a tourism context}

SRT, developed by Moscovici in the early 1960s, is based on Durkeim's (1898) concept of collective representations. It is concerned with the relationship between sociocultural intersubjectivity and the representations that are shared among individuals, community and culture (Moscovici, 1961). These are not individual, but constitute an object for a social group, and are expressed verbally or through overt behavior (Sugiman, 1997; Wagner et al., 1999). Moscovici (1976, p. 23) defines SR as "a system of values, ideas and practices with a twofold function: first, to establish an order which will enable individuals to orientate themselves in their material and social world and to master it; and secondly to enable 
communication to take place among the members of a community by providing them with a code for social exchange and a code for naming and classifying unambiguously the various aspects of their world and their individual group history."

SR originate in the field of sociology, although Moscovici (1984/2000) explains that they should rather be considered as a form of social psychology. Accordingly, sociologists knew about the existence of SR but considered them as static concepts of social reality, akin to the ideas of Aristotle, Kant and the Stoics; while social psychologists acknowledge them as a fluctuation of unifying systems, such as sciences, religion and ideologies. In other words, SRT advocates that shared realities and common sense are not only based on traditional ideas and beliefs only, but also on a particular mode of understanding and communication; which creates social and collective reality and common sense. Finally, this results in a shared system of meanings (O’Connor, 2017).

Moscovici (2001) adds that these SR can be divided into three types, namely hegemonic (emerging from groups with power and likely to dominate social reality and the media), emancipated (not shared by the whole population but popular within certain groups) and polemical (arising from conflict between social groups - e.g. as reactions to hegemonic representations). Hegemonic representations are commonly shared by most of the members of a society, nation or macro-unit (Moscovici, 1988). Höijer (2011) gives an example of climate change, which in contemporary society is arguably recognized as a problem by authorities, the media, and subsequently by a large subset of the population. Emancipated representations are related to subgroups which create their own versions with a certain degree of autonomy (Moscovici, 1988). An example is the representation of health and illness among traditional and alternative medicine, which are partly complementary and often combined by the public (Höijer, 2011). Polemical representations are related to social conflicts, struggles and controversies which are often antagonistic and seen as "mutually exclusive" (Moscovici, 1988). An example therefore could be the political ideas of communism and capitalism.

Höijer (2011) however adds that in reality, these distinctions are not exclusive as SR are often multifaceted and contradictory. Moskovici and Marková (2001) furthermore highlight that SR are volatile by nature and can transform over time; and as a consequence should not be too narrowly defined. This flexibility produces some theoretical ambiguities, which may have hindered the wider use of SRT in practical research (Voelklein \& Howarth, 2005).

A few examples of studies using SR are available in tourism, although the topics discussed and methods employed vary greatly. SR have been investigated in the context of stakeholder analysis (Moscardo, 2011), events (Fredline \& Faulkner, 2001), quality of life (Moscardo 2009), sustainability (Dickinson, Robbins, Filimonau, Hares, \& Mika, 2013), volunteer tourism (Aquino \& Andereck, 2018), and even the management of tourist selfies (Pearce \& Moscardo, 2015). However, although the theory is frequently mentioned, a deeper discussion of SR is often missing (Aquino \& Andereck, 2018).

Methods employed in these studies also differ greatly. Cluster analysis is a popular methodological tool (Andriotis \& Vaughan, 2003; Fredline \& Faulkner, 2000), while other studies have adopted qualitative or mixed methods (Aquino \& Andereck, 2018; Dickinson \& Dickinson, 2006; Dickinson \& Robbins, 2008; Lai, Morrison-Saunders, \& Grimstad, 2017; Schliephack \& Dickinson, 2017; Yuksel, Bramwell \& Yuksel, 1999). On a different base, Moscardo (2011) combines a content and semiotic analysis to identify SR in tourism planning. Sharpley (2014) finally adds that SR are commonly approached descriptively, without seeking an explanation as to why the community holds them.

Further light on the methodological flexibility of SRT is shed by Wagner et al., (1999), who compare six empirical SR studies across different fields. Methodological tools included 
ethnography, focus groups, interviews, media analysis, word association, quantitative questionnaires and experiments. Accordingly, events and phenomena get introduced into the life-course of social groups as social objects, which may at times be unfamiliar and threatening. Such social objects may require material coping, i.e. by designers and engineers (Moscovici, 1976; Wagner, Valencia \& Elejabarrieta, 1996), and symbolic coping, a psychosocial process at the heart of SRT. The first stage of this process is usually anchoring, by which an unfamiliar social object becomes familiar by attributing it a name and characteristics. This allows social groups to communicate and talk about a phenomenon (Wagner et al., 1999). For example, the emergence of AIDS was interpreted as a venereal disease by some groups of the population, and as a divine punishment by others. Anchoring, which was partly a function of the traditional media, has been enhanced and accelerated by the emergence of social media. The next step in constructing SR is objectification, where socially obtained knowledge attains its specific form through icons, metaphors or tropes. These characteristics, once established within a group, become guidelines for related discourse and behavior in daily life, adding a new SR to a group's life-world (Wagner et al., 1996).

It needs thus to be concluded that researching SR has various methodological implications. Because they are not entirely individual, social groups should be determined first in terms of their perceptions of a phenomenon, and this requires segmentation of the population based on their expressed attitudes in regard. SRT assumes that people prefer to communicate with others of similar opinion, refer to media sources which confirm their beliefs, and regard facts that do not fit their representation as less "real" than those that do (Joffe, 2003; Moscovici \& Hewstone, 1983; Schliephack \& Dickinson, 2017; Wagner et al., 1996). However, segmentation can only produce a descriptive understanding of SR (Sharpley, 2014). Qualitative study of different segments may give further insights, specifically how a SR is anchored and objectified. In addition, consulting experts, such as tourism academics may show the extent to which SR are hegemonic, emancipated, or polemical, and how information sources, such as government and the media, influence their creation. As a result, the goal of this study is to take the case of Vietnamese residents' attitude towards Chinese tourism in order to propose a three-step multiple-mixed-method approach for identifying and understanding underlying SR, which is presented as follows.

\section{METHODS}

In light of this conceptual discussion, a tripartite methodology for understanding SR in tourism is proposed in this section.

A multiple-mixed-method approach is offered, combining three stages of investigation in order to understand the SR of Chinese tourism for Vietnamese residents. Although not specifically related to SR, Wassler et al. (2018) proposed a method to investigate resident attitudes based on a two-step procedure; whereas the first step identifies social clusters and the second step uses "member-checking" interviews to gain a deeper insight into the identified segments of attitude formation. In this study, a 3-stage multiple-mixed method is proposed, which contextualizes the identified social representations through an additional round with relevant experts. Moscovici $(1984 ; 1988)$ highlights the importance of sociocultural, political and historical knowledge for a correct understanding of SR; and this final stage is aimed at strengthening the method in this regard. The approach is thus outlined as follows.

Stage 1 seeks to identify social clusters and any differences among them using a resident attitude towards Chinese tourism scale. Stage 2 employs interviews to examine how SR are 
anchored, objectified and incorporated into discourse and action. Vietnamese residents aged 18 years and above were eligible to participate in the first two stages. Central Vietnam was chosen to carry out the survey in stage 1 and interviews in stage 2; as this area witnessed not only the tremendous growth of Chinese tourism, but also the turbulent relationship between Chinese tourists and Vietnamese hosts in the last years (Giao Duc Viet Nam, 2014; Zing.vn, 2016; VOV, 2017). Stage 3 aims to contextualize and classify SR through interviews with experts; showing their overall relationship with residents' attitudes. Expert interviews were used to, firstly, acquire professional assessment on the findings of previous stages and, secondly, to obtain additional and/or reliable information for contextualizing the identified SR. Details of the data collection and analysis of each stage are presented below.

\section{Stage 1: Determination of social clusters in relation to the phenomenon under investigation}

A 12 item scale measuring residents' attitudes to Chinese inbound tourism was adapted from an instrument originally by Hanafiah, Jamaluddin, and Zulkifly (2013) and later adapted to and validated for a two-step procedure investigating residents' attitude towards tourism inbound policies in Hong Kong by Wassler et al. (2018); the latter being the original study to propose a combination of cluster analysis and qualitative research to understand residents' attitudes.

To sample residents for the survey, a non-probability sampling strategy - geographic quota sampling - was applied to 27 districts in Central Vietnam. This was done to maximize the diversity in the sample (Maxwell, 2005). In addition, a convenience sampling method was used to approach a maximum number of respondents. The survey was carried out throughout different residential areas by ten student helpers and yielded a total of 537 valid questionnaires. A two-stage clustering process was used, combining a hierarchical procedure, followed by a non-hierarchical procedure (Hair, Black, Babin \& Anderson, 2010). In the hierarchical technique, the stopping rule of Hair et al. (2010) was used to establish an appropriate number of clusters. This number was then applied in a non-hierarchical analysis to identify cluster membership. ANOVA and cross-tabulation using demographic variables established significant differences among the clusters. The variables used were age, gender, education, occupation, income, and involvement in tourism, all of which have been claimed as influencing residents' attitudes by other researchers.

\section{Stage 2: Understanding SR of the phenomenon under investigation}

In order to guarantee maximum variation and depth of information, quota as well as purposeful sampling techniques were applied for the qualitative interview stage. 5 to 10 informants were selected from each cluster for this purpose. Informants were selected based on their demographic characteristics, congruent with the segmentation of the first stage. A screening question on their support level for Chinese tourism to Vietnam (low support neutral - high support) was also asked to determine and confirm potential cluster membership. These individuals were confronted with findings from Stage 1, namely general attitudes and significant demographic differences among the identified clusters. Semistructured interviews allowed informants to give their interpretation of these findings, discuss how they objectified their perception of Chinese tourism in daily-life and comment on how they anchored these social objects through concepts such as culture, history, economics and politics. Questions related to objectification typically asked informants to describe instances where they had been confronted, directly or indirectly, with the Chinese tourism phenomenon. Anchoring was examined by asking interviewees to give a rationale for their observations. Interviews were furthermore kept semi-structured so that new SR might emerge from the discussion. In this way it was possible to identify a range of anchored and objectified SR of Chinese tourism which were relevant in different ways to all of the clusters identified in Stage 
1.

Stage 3: Contextualizing SR of the phenomenon under investigation

At this stage, purposeful sampling was used to ensure diverse and comprehensive information (Maxwell, 2005). Vietnamese experts in the field of tourism and related areas working at universities in Vietnam, Macao and the UK and other countries were invited to be interviewed on the findings of the previous two stages. SR identified in the previous stages of the research were presented one by one and informants were asked to discuss their nature, their formation, and their likely impact upon different sectors of the local population. Finally, the experts were asked to give their opinions on residents' attitudes towards Chinese tourism in Vietnam.

Findings from the three stages were finally combined into an overview of the identified SR in terms of their nature, anchoring, objectification, and distribution among the different clusters. This offers a clearer view of the hegemonic, emancipated or polemical nature of the SR and of the underlying mechanisms of their overall attitude formation.

\section{FINDINGS AND DISCUSSION}

\section{Stage 1: Determination of social clusters}

Among the 536 valid questionnaires obtained from the survey, the majority of respondents $(68 \%)$ were under 35 years old. There were slightly more female $(56.5 \%)$ than male $(43.5 \%)$ respondents; $78 \%$ held bachelor or higher degrees and $38 \%$ claimed to be involved in tourism. Attitudes to Chinese inbound tourism tended toward the mid-point (3.78 to 4.45) on a 7-point Likert scale.

Factor analysis of the 536 cases produced only one component from the 12 items, explaining $67.1 \%$. of the total variance, with Cronbach alpha 0.955, and therefore, all 12 items were included in the cluster analysis (as shown in table 1). A three-cluster solution was chosen from the hierarchical clustering process, based on the greatest percentage changes in heterogeneity. The 536 cases were then analysed using a non-hierarchical clustering method from which were obtained: a positively disposed "High-support" group (cluster 1), a negatively disposed "Low-support" group (cluster 2) and a "Neutral" group (cluster 3). Final cluster centers were at 5.4, 2.0 and 3.8 respectively, based on the 7-point scale. The Highsupport group was the largest $(\mathrm{N}=213,39.7 \%)$, followed by the Neutral group $(\mathrm{N}=209$, $38.9 \%)$ and the Low-support group $(\mathrm{n}=115,21.4 \%)$ (as shown in table 1). Cross-tabulation and ANOVA were used to profile the clusters in terms of gender, age, education, occupation, income and involvement in tourism. In Table 2, it can be seen that a substantial proportion of High-support group members $(41.3 \%)$ were under 24 years old and many were university students $(30.5 \%)$. The Low-support group were slightly older, with $39.1 \%$ between $25-34$, and they tended to be employees $(30.4 \%)$ or business people $(20.9 \%)$. The profile of the Neutral group was closer to the High-support than to the Low-support group. Differences between the clusters in terms of age, education, occupation and income were significant at 0.10 level. This significance level was used due to the granular nature of demographic comparisons using chi-squares and is deemed as commonly acceptable (Hair et al., 2010). Younger, less educated and lower income respondents tended to have a more positive attitude towards Chinese inbound tourism and attitudes would get more negative the older, more educated and higher income respondents became.

Table 1. The results of Factor Analysis and Cluster Analysis

\begin{tabular}{cccccc} 
Factor & \multicolumn{3}{c}{ Final Cluster Centers } & \multicolumn{2}{c}{ ANOVA } \\
\cline { 2 - 7 } loadings & $\mathbf{1}$ & $\mathbf{2}$ & $\mathbf{3}$ & F & Sig.
\end{tabular}




\begin{tabular}{|c|c|c|c|c|c|c|}
\hline $\begin{array}{l}\text { The tourism industry in Vietnam should be } \\
\text { actively developed through attracting } \\
\text { Chinese market }\end{array}$ & 0.747 & 5.25 & 2.36 & 4.00 & 214.624 & 0.000 \\
\hline $\begin{array}{l}\text { I support Chinese tourism to Vietnam and } \\
\text { would like to see it become an important tool } \\
\text { for Vietnam tourism development }\end{array}$ & 0.820 & 5.47 & 2.17 & 4.02 & 341.459 & 0.000 \\
\hline $\begin{array}{l}\text { I support Chinese tourism to Vietnam as it } \\
\text { will attract more tourists in general }\end{array}$ & 0.801 & 5.70 & 2.24 & 4.25 & 326.914 & 0.000 \\
\hline $\begin{array}{l}\text { I believe that Chinese tourism to Vietnam } \\
\text { should be actively encouraged }\end{array}$ & 0.806 & 5.46 & 2.31 & 4.12 & 313.194 & 0.000 \\
\hline $\begin{array}{l}\text { Vietnam residents should support the } \\
\text { promotion of Vietnam tourism to Chinese } \\
\text { market }\end{array}$ & 0.803 & 5.61 & 2.35 & 4.42 & 332.928 & 0.000 \\
\hline $\begin{array}{l}\text { Vietnam can become a more developed } \\
\text { tourism destination through China market }\end{array}$ & 0.852 & 5.24 & 1.84 & 3.75 & 389.742 & 0.000 \\
\hline $\begin{array}{l}\text { In a long term, Chinese tourism to Vietnam } \\
\text { will exaggerate the tourism business }\end{array}$ & 0.840 & 5.49 & 2.03 & 3.99 & 397.188 & 0.000 \\
\hline $\begin{array}{l}\text { Chinese tourism to Vietnam helps to increase } \\
\text { the quality of life and standard of living for } \\
\text { residents in Vietnam }\end{array}$ & 0.840 & 5.26 & 1.82 & 3.34 & 388.463 & 0.000 \\
\hline $\begin{array}{l}\text { It is important to manage the growth of } \\
\text { tourism in Vietnam trough attracting more } \\
\text { tourism from China }\end{array}$ & 0.867 & 5.31 & 1.79 & 3.59 & 463.226 & 0.000 \\
\hline $\begin{array}{l}\text { I believe Chinese tourism to Vietnam plays a } \\
\text { major role in the economy of Vietnam }\end{array}$ & 0.841 & 5.18 & 1.77 & 3.36 & 398.059 & 0.000 \\
\hline $\begin{array}{l}\text { Generally, the positive benefit of Chinese } \\
\text { tourism to Vietnam outweighs the negative } \\
\text { impact }\end{array}$ & 0.775 & 5.20 & 2.05 & 3.67 & 277.909 & 0.000 \\
\hline $\begin{array}{l}\text { The future of Vietnam as a tourist destination } \\
\text { is sustainable with targeting tourists from } \\
\text { China }\end{array}$ & 0.828 & 5.34 & 1.85 & 3.45 & 386.041 & 0.000 \\
\hline
\end{tabular}


Table 2. Clusters' profile and Pearson Chi-square results for validation

\begin{tabular}{|c|c|c|c|c|c|c|}
\hline & \multicolumn{4}{|c|}{$\begin{array}{l}\text { Cluster } 1 \text { High-Support Cluster } 2 \text { Low-support } \\
(\mathrm{N}=\mathbf{2 1 3})\end{array}$} & \multicolumn{2}{|c|}{$\begin{array}{c}\text { Cluster } 3 \text { Neutra } \\
(\mathrm{N}=209)\end{array}$} \\
\hline & $\mathbf{N}$ & $(\%)$ & $\mathbf{N}$ & $(\%)$ & $\mathbf{N}$ & $(\%)$ \\
\hline Gender & $p=0.305$ & & & & & \\
\hline Male & 87 & $(40.8)$ & 57 & $(49.6)$ & 89 & $(42.6)$ \\
\hline Female & 126 & $(59.2)$ & 58 & $(50.4)$ & 119 & $(56.9)$ \\
\hline Missing & & & & & 1 & $(0.5)$ \\
\hline Age & $p=0.091$ & & & & & \\
\hline $18-24$ & 88 & $(41.3)$ & 27 & $(23.5)$ & 80 & $(38.3)$ \\
\hline $25-34$ & 57 & $(26.8)$ & 45 & $(39.1)$ & 69 & $(33.0)$ \\
\hline $35-44$ & 28 & $(13.1)$ & 14 & $(12.2)$ & 21 & $(10.0)$ \\
\hline $45-54$ & 22 & $(10.3)$ & 12 & $(10.4)$ & 19 & $(9.1)$ \\
\hline $55-64$ & 14 & $(6.6)$ & 12 & $(10.4)$ & 15 & $(7.2)$ \\
\hline Above 65 & 4 & (1.9) & 5 & $(4.3)$ & 4 & (1.9) \\
\hline Missing & & & & & 1 & $(0.5)$ \\
\hline Education & $p=0.088$ & & & & & \\
\hline Primary school & 11 & $(5.2)$ & 4 & $(3.5)$ & 2 & $(1.0)$ \\
\hline Secondary/high school & 42 & (19.7) & 25 & $(21.7)$ & 30 & $(14.4)$ \\
\hline College/university & 132 & $(62.0)$ & 67 & $(58.3)$ & 140 & $(67.0)$ \\
\hline Postgraduate & 26 & $(12.2)$ & 19 & $(16.5)$ & 33 & $(15.8)$ \\
\hline Missing & 2 & $(0.9)$ & & & 4 & $(1.9)$ \\
\hline Occupation & $p=0.003$ & & & & & \\
\hline Employee/worker & 45 & $(21.1)$ & 35 & $(30.4)$ & 68 & $(32.5)$ \\
\hline Businessperson & 35 & $(16.4)$ & 24 & $(20.9)$ & 29 & (13.9) \\
\hline Agricultural worker & 13 & $(6.1)$ & 3 & $(2.6)$ & 6 & $(2.9)$ \\
\hline Freelancer & 34 & (16) & 17 & $(14.8)$ & 15 & $(7.2)$ \\
\hline Retired & 5 & $(2.3)$ & 9 & $(7.8)$ & 13 & $(6.2)$ \\
\hline Student & 65 & $(30.5)$ & 19 & $(16.5)$ & 56 & $(26.8)$ \\
\hline Unemployed & 3 & $(1.4)$ & 1 & $(0.9)$ & 4 & $(1.9)$ \\
\hline Other & 10 & $(4.7)$ & 5 & $(4.3)$ & 17 & $(8.1)$ \\
\hline Missing & 3 & $(1.4)$ & 2 & $(1.7)$ & 1 & $(0.5)$ \\
\hline Income & $p=0.067$ & & & & & \\
\hline < 1 mil. dong & 68 & $(31.9)$ & 19 & $(16.5)$ & 51 & $(24.4)$ \\
\hline 1 - 2 mil. dong & 30 & $(14.1)$ & 18 & (15.7) & 19 & $(9.1)$ \\
\hline 2 - 4 mil. dong & 58 & $(27.2)$ & 31 & $(27)$ & 58 & $(27.8)$ \\
\hline 4 - 6 mil. dong & 31 & $(14.6)$ & 23 & (20) & 43 & $(20.6)$ \\
\hline 6 - 8 mil. dong & 15 & $(7)$ & 15 & (13) & 22 & $(10.5)$ \\
\hline$>8$ mil. dong & 9 & $(4.2)$ & 8 & (7) & 14 & $(6.7)$ \\
\hline Missing & 2 & $(0.9)$ & 1 & $(0.9)$ & 2 & $(1.0)$ \\
\hline Involvement in tourism & $p=0.667$ & & & & & \\
\hline Yes & 85 & $(39.9)$ & 46 & $(40)$ & 75 & $(35.9)$ \\
\hline No & 128 & $(60.1)$ & 69 & $(60)$ & 133 & $(63.6)$ \\
\hline Missing & & & & & 1 & $(0.5)$ \\
\hline
\end{tabular}




\section{Stage 2: Interviews of selected informants}

A total of 20 interviewees were recruited: 7 each from the Low- and High-support clusters and 6 from the Neutral group, according to the member-checking process proposed by Wassler et al. (2018). Interviews were carried out throughout April and May 2018 in Vietnamese language. They were recorded, transcribed, translated into English and the translations cross-checked by two bilingual researchers. All interviews were semi-structured and questions were developed around the following broad themes: (1) personal views on Chinese tourism in Vietnam, (2) assessment of the identified social clusters, and (3) contextual information. As this stage was largely exploratory, inductive coding was applied to the transcripts in the research software Nvivo. The data was coded separately by two researchers and identified themes have been compared for validation purposes. Five SR relating to resident attitudes towards Chinese tourism were identified, and anchorings and objectifications of these representations were explored.

The first SR, shared by informants from all three clusters, was that of Chinese tourism as "A Confrontation with the Eternal Enemy". This belief that China and Vietnam are intrinsically destined to live in conflict was anchored mainly through historical and political concepts. For instance, one informant claimed that to have "read a lot of books and I understand the relationship between China and Vietnam well; and I never like them [Chinese] since". Another said: "history leaves a mark of hatred", referring to historical incidents such as wars and colonialism between the two countries. Interviewees also pointed to contemporary political issues between China and Vietnam in the South China Sea. This SR was objectified in two ways, the first being first or second-hand encounters where Chinese tourists were unfriendly or disrespected Vietnamese culture. Informants said that Chinese tourists "are very closed when they travel" and misbehave, for example by "spitting on the ground in heritage sites". Secondly, tourism was seen as a kind of invasion, objectivized as a type of "tourist colonization"; such as in Saigon and Nha Trang, where Chinese were said to "have imposed their own way of life on the place" and to "bring their own culture" rather than adapting to the local customs.

The second SR “Vietnamese Mismanagement” was mostly mentioned by informants from the Neutral and Low-support clusters. It was based on a belief that contemporary Vietnam is not able to manage Chinese tourism properly and was anchored in perceptions of culture and politics. In terms of culture, one informant underlined Vietnamese short-term thinking, where "we see only the short-term benefits. We only see the money flow in, we are greedy in some sense, and you can say that". This was objectified in terms of earnings: "lower-income people often have their income raised through a large number of Chinese tourists in Vietnam, so they have no option but to support Chinese tourism". Politically, informants felt that Vietnam did not have proper policies in place to deal with the impact of Chinese mass-tourism and anchored this in the notion that the Vietnamese government shared the short-term thinking they associated with Vietnamese culture. One informant summarized it as "bad abilities of tourism management of the Vietnamese government". The representation was objectified through issues such as a failure to attract high-spending Chinese tourists: "we are just receiving some common, middle-income groups of Chinese tourists, who spend little when travelling and leave a high impact afterwards." With this management, an interviewee warned "you will see the negative impacts in the long run, just wait and see".

The third SR, mostly confined to the Low-support cluster, represented Chinese tourism as "Another Made-in-China". Anchored in history and politics, this representation was objectified mostly through the belief that anything from China was inherently bad and "made in China" implied a stigma on a product or service. Accordingly, one interviewee said: "I will 
not support Chinese tourism because there have been so many negative images about China everywhere in Vietnam". Another noted "most people just hate Chinese tourism and anything related. Just knowing that it is Chinese they hate it. Like anything labelled "Chinese", we have a bad feeling about it". Specific objectifications were offered, such as Chinese tourism crowding out other tourist groups in Vietnamese destinations: "I worked in Saigon and other big cities for years. You see the effects of Chinese tourism, as well as of Chinese people at a destination. They distort places and what is worse, they impose their own way of life and culture on the place. They transform the place into theirs in some sense". Another said that, since Chinese tourism increased in Da Nang and Nha Trang, "good relaxing things" for other types of tourists have disappeared. Another objectification was that Chinese tourists spend money only in Chinese enterprises, rather than benefitting the Vietnamese, as they "stick to their own Chinese-related service providers at any place they go"; mirroring the representation of tourism as a form of neo-colonialism by an eternal enemy.

The fourth SR, mainly among the High-support and Neutral clusters, saw Chinese tourism as an "Important Source of Income", anchored in its supposed economic value. Informants mentioned that "the main reason for support is the income" and "to some certain extent, they [Chinese tourists] do bring revenue for our tourism sector. We cannot deny that". Another specified that "tourism ... is about money, income and jobs. There are many benefits and there are realistic people who only care about where we can generate income, where we can earn benefits". This SR was objectified through the Chinese tourist being typically perceived as a high-spender. Interviewees mentioned that they believed Chinese tourists to be "shopping a lot" and Chinese in general "becoming rich and spending a lot right now." Others specified overall economic benefits of working with China, quoting an advertisement which stated that "when working for Chinese companies here in Vietnam, you will have a higher salary plus various benefits. Your job is secured and there is always a high demand for employment".

The fifth, final SR saw Chinese tourism as "an opportunity to explore Chinese culture". This idea was mostly confined to the High-support group and was anchored in historical and modern culture. While some interviewees objectified this representation from China's historical relationship with Vietnam, modern Chinese culture was frequently mentioned as a source of interest and direct contact. One informant said that particularly the younger Vietnamese "care about those Korean and Chinese singers and movies, their fashion and how they present themselves. They just go with those who look rich and beautiful". Another stated that Chinese "movies, dramas and music draw out illusions for them [the younger Vietnamese]." One interviewee said "they [young Vietnamese] will show more support for Chinese tourism. They are strongly affected by the Chinese entertainment industry; they adore Chinese actors and actresses or singers. In fact, they are crazy about them. They have more access to the internet, they follow Chinese new trends; thus, they are more open-minded towards Chinese tourism".

Stage 3: Contextualizing SR of the phenomenon under investigation

Seven experts in relevant areas of study were recruited for the data collection in this stage. All were Vietnamese nationals, working at universities in Vietnam, China (Macao) and the UK. Interviews with the experts were conducted in September 2018 and the profile of the participants is presented in table 3 below. 
Table 3. Profile of the experts

\begin{tabular}{llll}
\hline Expert & Gender & Age group & Profession \\
\hline 1 & M & $35-45$ & Assistant Professor, Macao \\
2 & F & $25-35$ & Lecturer, UK \\
3 & M & $35-45$ & Associate Professor, Vietnam \\
4 & F & $25-35$ & Lecturer, Vietnam \\
5 & F & $35-45$ & Associate Professor, Vietnam \\
6 & M & $25-35$ & Lecturer, Vietnam \\
7 & F & $25-35$ & Lecturer, Vietnam \\
\hline
\end{tabular}

These expert informants were invited to discuss and contextualize the findings from the previous two stages of research. Interviews were conducted in Vietnamese, recorded, transcribed, translated, and cross checked, as for the previous interviews. Interviews were again semi-structured and questions were developed around the following topics: (1) assessment of the identified social clusters, (2) opinions on the identified social representations, and (3) contextual information. As several SR had been identified through inductive coding in stage 2, transcripts of the expert interviews were coded deductively in Nvivo by two separate researchers for validity purposes. However, new themes were allowed to emerge if these were raised by the interviewees. Finally, this made it possible to identify the different SR as hegemonic, polemical, emancipated or a mixture of these and give an overall view of SR underlying attitude formation (see Figure 1); whereas hegemonic SR emerge from groups with power and are likely to dominate social reality and the media, emancipated SR are not general but popular within certain groups and polemical SR arise from conflict between social groups (Moscovici, 2001).

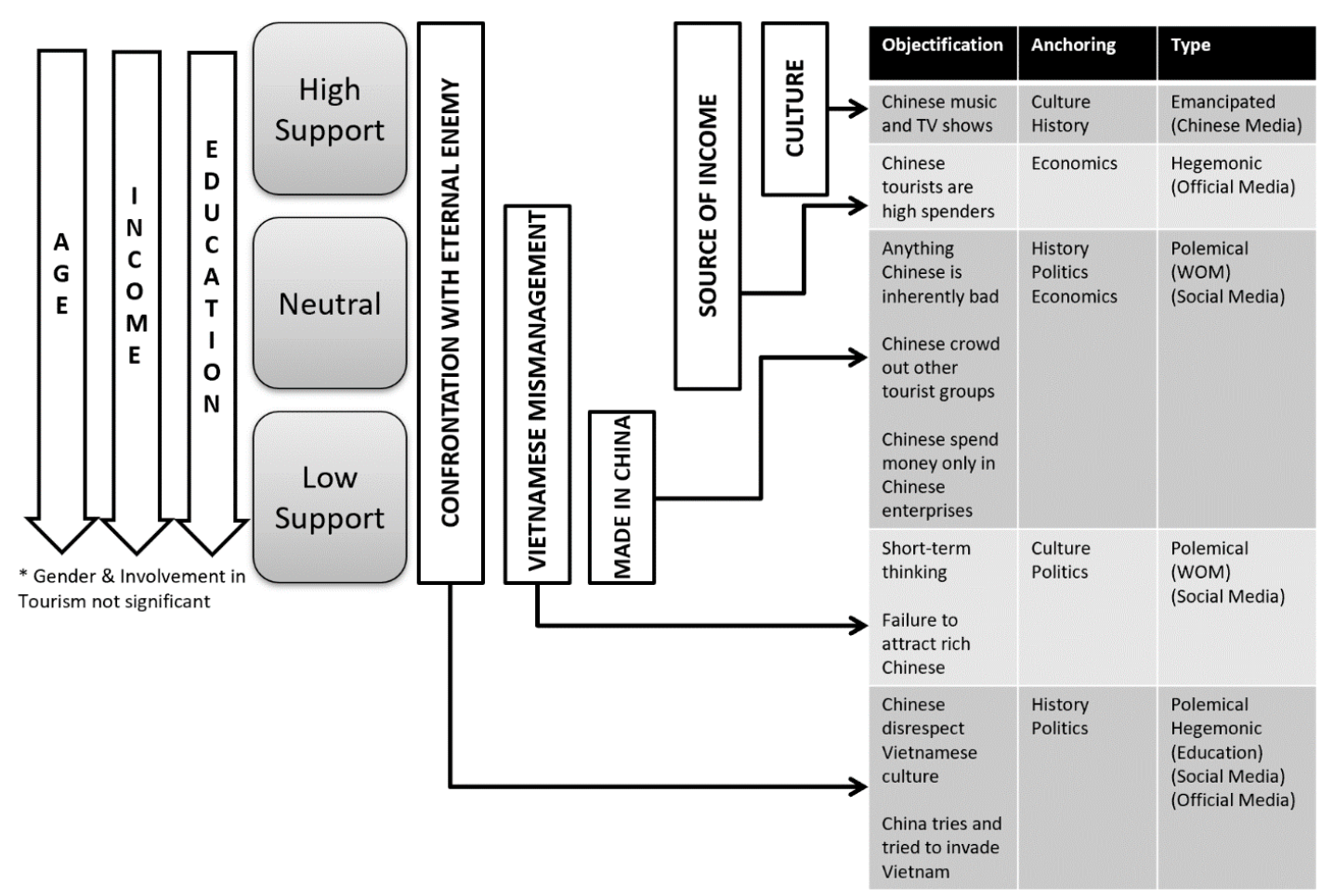

Figure 1: SR forming Vietnamese Host Attitudes Towards Chinese Tourism 
As mentioned above, an analysis of demographic differences showed positive attitudes to Chinese tourism diminishing as age, income and level of education increased; whereas gender and involvement in tourism were not found to be significant. In past host attitude studies, a majority of these variables have been found to have a minor effect only (Perdue et al., 1990). However, linking them to the SR of different clusters has shown interesting findings.

SR are generally considered to be woven across social groups (Sugiman, 1997; Wagner et al., 1999), but in the present case they were identified within attitude clusters, which functioned as a type of social group in relation to Chinese tourism. Interviewed experts explained the cluster differences and their influence on forming relevant SR as being related to a changing stance in a hegemonic source of information: the official Vietnamese media. As noted in this study, most Vietnamese above 25 years of age were subjected to education and media reports portraying China as the "eternal enemy", largely in order to boost Vietnamese patriotism by showing a distinct cultural identity. One expert noted: "Actually, it was not the intention of the Vietnamese authorities to create a negative image of China, or any country. The focus was on the strong character of Vietnamese, who can fight any invaders. And they want to portray this convention to stem from a really long time ago, so that our character is strong and tough; and China has had a long relationship with Vietnam. In the 90 's Vietnam tried to build an image which is separated from China and I think there were some events which made Vietnam want to be independent from China. Therefore, the authorities tried to highlight certain events in history and promoted Vietnamese folk culture".

It was further suggested that the SR of China as enemy reflected a deeper division among political affiliations within Vietnam, China being represented as an ideological enemy by anti-establishment groups. "In recent years, there are two political groups, one is close to China - communism - and the other is related to democratic campaigns. The latter group uses negative news of China for their campaign. They write and spread a lot of news that affect people's attitudes towards China and the Chinese". Indeed, the Vietnamese government recently had to deal with public outrage after negotiating the opening of new Special Economic Zones for Chinese trade in Vietnam, being accused by the public of having "become too cosy with fellow communists in the north" (Murray, 2018, p.1).

Expert informants pointed out that some SR reflected a more favorable official stance towards Chinese tourism. For instance, objectifications such as "Another Made in China" for Chinese tourism used to be hegemonic, i.e. promoted by Vietnamese official media; but are now mostly emancipated in character, being propagated through word-of-mouth (WOM) and social media. An expert explained that this partly due to a changing government attitude toward Chinese tourism: "In fact, VNAT [Vietnam National Administration of Tourism] has acknowledged the fact that locals do not support Chinese tourism; they specifically scammed Chinese tourists, such as a case in Ha Long. VNAT has thus called for a fair treatment of Chinese tourists and tourists' satisfaction should come first. In theory, it is the right thing to do. However, the negative Chinese image has been established and the influence from (other) media is too strong. So, it is inevitable to have a bias".

Experts pointed out that perceptions of China and Chinese tourism in Vietnam were contradictory, as is often the case for coexisting SR (Höijer, 2011; Joffe, 2003; Moscovici \& Hewstone, 1983; Schliephack \& Dickinson, 2017). An expert specified that "Currently news and information in Vietnam are really messy, including the ones from the official media [...]. They sometimes post incorrect news as well. And sometimes, news on Facebook are more accurate. I don't know which one is more reliable, I always read from different sources for verification". 
While representations of China as the "eternal enemy" are also still favored in part by official media and education, "Chinese tourism as a confrontation with the eternal enemy" is shifting to resemble Moscovici's (2001) "polemical representations"; i.e. an irritated reaction to the changing hegemonic narrative - shared by the locals through alternative media. Indeed, support for anything Chinese has caused massive public outcries in Vietnam, often culminating in protests against the local government and making Vietnamese authorities cautious about supporting China publicly (Vu, Nguyen, \& Ruwitch, 2018).

The clusters identified in this study show that in a significant part of the population negative SR of Chinese tourism coexist with more positive ones. Interestingly, direct financial benefit from Chinese tourism did not seem related to overall stance, as involvement in tourism was not found to affect attitudes significantly. This supports Boley, McGehee, Perdue and Long's (2014), as well as Gibson, Walker, Thap, Kaplanidou, Geldenhuys and Coetzee's (2014) conclusion that maximization of economic advantage and personal experience are often overshadowed by socially transmitted values. It also suggests that first-hand interaction between host and guest is a not a crucial factor for host-attitude formation (Sharpley, 2014; Woosnam, 2012), but that it is more likely connected to collective, ideological beliefs and stances, such as SR.

Experts suggested that this non-reliance on, or absence of, first-hand experience creates a somewhat neutral attitude among a majority: "In general, there are a lot of people who are neutral towards Chinese tourism. They normally support tourism development as they see the economic benefits. So, they might think Chinese tourists come and bring along economic benefits to the destination; but they receive information from sources such as news, with a great deal of aversion to [the] Chinese; so they keep a neutral attitude. On one side, they think Chinese tourists could bring economic benefits, on the other hand, negative information on Chinese tourists spreads widely and they also think of negative effects on other aspects, such as social and environmental. So, in the end, they are neutral. I also see lots of tourism experts hold neutral attitudes regarding this issue". Experts also mentioned that the financial benefits of Chinese tourism are now hegemonically represented the official media, as the government view of China becomes more favorable, whereas alternative media are more critical in this regard.

Another favorable SR among the High-support cluster was an "opportunity to explore Chinese culture", because "China has a big entertainment industry producing lots of movies and music, idols, celebrities or music bands. Young generations [of Vietnamese] access this entertainment information much more often than political, historic or cultural ones. So, when they like their Chinese idols they would not think negatively about Chinese people and thus tourism". Interviewed experts agreed that China is particularly popular among the younger Vietnamese and such a manifestation can be considered as an "emancipated SR" (Moscovici, 2001), as it often stems directly from the Chinese media and is popular only for a particular sub-group of the population.

One expert pointed out an interesting divide in interpretations of Chinese culture. He noted that younger Vietnamese were more sympathetic towards contemporary China, and thus contemporary tourists, while older individuals associated China with traditional culture, which is less represented by the modern tourist. This may be connected with the fall in positive attitude for Chinese tourism with advancing age: "They [younger Vietnamese] read a lot Chinese books, news and other materials, they are not totally against Chinese. Older people only like 'Han' culture [traditional Chinese culture] and do not like contemporary Chinese culture, so they are against tourism". The anchoring of this specific SR can thus be interpreted in modern and traditional Chinese culture respectively. 
China is currently using soft power aggressively to gain social and political support around the globe, often in the form of popular culture, such as TV shows and pop music (Nantulya, 2018; Peng, 2012). So far this has had only moderate success in the West, but in Africa and Southeast Asia the impact in recent years has been dramatic (Lanteigne, 2018). This is particularly relevant in Vietnam, where Chinese culture can be rooted in a familiar cultural and political context: "They [Chinese] tried to build a better image of Chinese and it seems that they have succeeded. This also is true with the game industry, as many Chinese games are popular in Vietnam. Slowly, there will be a younger generation who will be against the 'boycott China' campaign. There is also a trend to study in China under scholarships". Expert informants believed that this, in addition to the SR of Chinese tourism as a valuable economic resource, propagated by Vietnamese media, may explain the more positive attitudes of the younger (and as a consequence of age) less educated and lower income population: "Vietnamese watch a lot of Chinese movies as well as Korean ones. And when watching movies from a certain culture you understand more about that culture. Especially, the Chinese and Korean cultures are close to Vietnam. This can be an explanation why younger generations have sympathy and welcome Chinese tourists".

\section{CONCLUSION}

This study has tested a three-step multiple-mixed-method, which (1) determined social clusters on the basis of their attitudes to Chinese tourism in Vietnam, (2) delineated SR of Chinese tourism through member-checking interviews with cluster members, and (3) contextualized these SR through interviews with tourism experts.

Three clusters were identified, respectively holding more positive, neutral and more negative attitudes towards Chinese tourism. Five SR were identified and explained in terms of their objectification, anchoring and type, as well as in their relationship with their identified attitude-clusters and demographic differences among them. Findings showed that different, sometimes even contradicting, SR of Chinese tourism held by Vietnamese residents were involved in the formation of these attitudes. Residents' attitudes towards Chinese tourism were also related to SR of China in general, whereas residents' involvement in tourism had no significantly effect on their attitude. This contradicted the widely-held assumption that financial benefit is the most salient variable in forming resident attitudes towards tourism (Williams \& Lawson, 2001).

Changing Vietnamese government narratives, plus an increase in Chinese soft-power have created higher levels of support for Chinese tourism, particularly among younger, lowerincome and lower-education groups. Negative representations of Chinese tourism (and China in general), while largely hegemonic in the past, appeared to be becoming more polemical, shifting towards alternative media and WOM and persisted among older, higher-income and higher-education groups. Conflicting SR resulted in a neutral attitude among the majority of the Vietnamese population.

The theoretical contributions of this study are thus as follows. First, it demonstrates a practical way to identify and characterize SR upon a strong theoretical base, overcoming some of the objections that have been levelled at previous studies (Zhang et al., 2006; Sharpley, 2014; Voelklein \& Howarth, 2005). Cluster analysis has been used previously in SR studies Andriotis \& Vaughan, 2003; Fredline \& Faulkner, 2000), but usually results in a merely descriptive account. This study employed a two-stage clustering process to identify groups holding different attitudes within a community (Moscovici, 1963, Sugiman, 1997; Wagner et al., 1999). Next, residents' symbolic coping through anchoring and objectification was examined through interviews with members from each attitude cluster (Moscovici, 1976; Wagner et al., 1999). Furthermore, expert interviews permitted contextual understanding of 
the SR identified, particularly in relation to the types of representations given. This made it possible fully to apply the advantages of SRT in a tourism context, providing a better understanding of social context, power and control (Moscovici, 1988; 2001); finally offering a reliable multi-mixed-method approach to investigate SR.

Finally, the novel method proposed can be applied in future studies. Resident research has often been largely quantitative and descriptive in nature (Sharpley, 2014). The multiplemixed-method developed in this research can complement large-scale quantitative models to unpack their findings and offer potential narratives of social psychology to ground and contextualize them. This can be applied to resident studies in a tourism context, but also to investigate SR of any other stakeholder group in tourism and beyond. In particular, SRT has often been confined to a European academic context as many of its mayor works have been written in French and are seldom translated to English (Duveen, 2000). It is hoped that the theoretical contributions given by this method may thus extend the applicability of SRT across different disciplines and linguistic contexts.

This study may also be of practical use. Residents are one of the most important stakeholders in the tourism decision making process (Kavaratzis, 2004), but are often described as the most difficult to deal with (Braun, Kavaratzis, \& Zenker, 2013; Merrilees, Miller, Herington \& Smith, 2007). If host-attitudes towards tourism are negative, residents may sabotage tourism development, whereas positive attitudes can transform residents into a destination's most valuable ambassadors (Kemp, Childers, \& Williams, 2012; Simpson \& Siguaw, 2008; Wassler \& Hung, 2017). This study offers thus a valuable tool by which management authorities can understand residents' attitudes towards tourism development. Furthermore, by identifying SR as hegemonic, emancipated and polemic, eventual sources for (mis)information can be determined and investigated.

This is particularly relevant in times where social media, online groups and on-line polls have increasing influences over public opinions (Bower, 2017). Fedeli (2019) highlights that, in a tourism context, the phenomenon of "fake news" has increasingly had practical impacts. He cites fake information about a volcanic eruption in Bali and diverging versions of political propaganda following the murder of a Polish tourist in Egypt as significant instances where the tourism industry was directly affected. SR give an insight into the social psychology of interested groups (Moscovici, 1984/2000), and findings of this study have shown that the proposed method can give practical insights on the nature and origins of the SR underlying certain phenomena. In particular, recognizing media actors divulging "fake news" and avoiding mendacious advertising and defamation will be increasingly important in a tourism context (Fedeli, 2019).

This leads to an array of future research opportunities. First, the proposed multiple-mixedmethod can be applied to different geographic, socio-political and cultural context to investigate its' applicability and eventual congruence of findings. Researchers are also invited to possibly revise the proposed method if the study context would demand it. Second, findings have shown that there is a complex interplay between SR, attitudes, demographic variables and contextual factors in forming residents' attitudes. Future studies could investigate how SET and other frameworks, such as Weber's theory of formal and substantive rationality, interplay with these factors. Finally, we want to invite scholars to apply the method to different stakeholders within and outside the field of tourism, investigating its validity as a tool for understanding social psychology in wide range of multidisciplinary research.

Finally, this study must acknowledge several limitations. First, several sociodemographic variables which have been found to condition host-attitudes in past studies have not been considered in this research; include the stage of tourism development, type of tourists, 
distance from tourism zones and geographical proximity to tourism centers. These have been shown as relevant in past studies and might have conditioned host attitudes in this case.

Second, this study chose the case of Chinese inbound tourism in Vietnam, which has a highly complex political, historical and geographic context. The strong influence of SR on forming host attitudes in this case might not be the same in locations where fewer contextual factors are involved. Third, respondents in the first stage of research were approached through convenience sampling. While this is an effective method to gather large number of responses, respondents might not properly reflect demographic distributions of the overall population. Indeed, the proportion of respondents holding a university degree was higher than the national average; this could possibly bias the accuracy of the findings. Follow-up studies could base their data collection on quota samples, taking characteristics of the host population into account. Finally, SR are by nature unstable, contradictory and constantly changing; posing another challenge to tourism management organizations. The findings of this study should thus be considered only a temporary snapshot of the most important SR of Chinese tourism in Vietnam. Further studies could investigate how to moderate and govern such passive and ever-changing influences on residents' attitudes. 


\section{REFERENCES}

Aguilo Pérez, E., \& Rosselló Nadal, J. (2005). Host community perceptions a cluster analysis. Annals of Tourism Research, 32(4), 925-941.

Andereck, K. L., Valentine, K. M., Knopf, R. C., \& Vogt, C. A. (2005). Residents' perceptions of community tourism impacts. Annals of Tourism Research, 32(4), 10561076.

Andriotis, K., \& Vaughan, R. D. (2003). Urban residents' attitudes toward tourism development: The case of Crete. Journal of Travel Research, 42(2), 172-185.

Ap, J. (1990). Residents' perceptions research on the social impacts of tourism. Annals of Tourism Research, 17(4), 610-616.

Ap, J. (1992). Residents' perceptions on tourism impacts. Annals of Tourism Research, 19(4), 665-690.

Aquino, J. F., \& Andereck, K. (2018). Volunteer tourists' perceptions of their impacts on marginalized communities. Journal of Sustainable Tourism, 26(11), 1967-1983.

Belisle, F. J., \& Hoy, D. R. (1980). The perceived impact of tourism by residents a case study in Santa Marta, Colombia. Annals of Tourism Research, 7(1), 83-101.

Boley, B. B., McGehee, N. G., Perdue, R. R., \& Long, P. (2014). Empowerment and resident attitudes toward tourism: Strengthening the theoretical foundation through a Weberian lens. Annals of Tourism Research, 49, 33-50.

Bower, E. (2017). Fake news, conspiracies, and the mysterious death of Magdalena Zuk. http://www.independent.co.uk/News/long_reads/fake-news-conspiraciesdeath-ofmagdalena-zuk-in-an-egyptian-resort-rape-far-right-marsa-alam-polish-a 7748971.html.

Braun, E., Kavaratzis, M., \& Zenker, S. (2013). My city-my brand: The different roles of residents in place branding. Journal of Place Management and Development, 6(1), 18-28.

Brida, J. G., Osti, L., \& Barquet, A. (2010). Segmenting resident perceptions towards tourism - a cluster analysis with a multinomial logit model of a mountain community. International Journal of Tourism Research, 12(5), 591-602.

Brotherton, B. (2008). Researching tourism and hospitality: A student guide. Thousand Oaks, CA: Sage

Butler, R. W. (1980). The Concept of a Tourist Area Cycle of Evolution: Implications for Management of Resources. Canadian Geographer, 24 (1) (1980), pp. 5-12

Chen, S., \& Raab, C. (2012). Predicting resident intentions to support community tourism: Toward an integration of two theories. Journal of Hospitality Marketing \& Management, 21(3), 270-294.

Choi, H. C., \& Murray, I. (2010). Resident attitudes toward sustainable community tourism. Journal of Sustainable Tourism, 18(4), 575-594.

Choi, H. S. C., \& Sirakaya, E. (2005). Measuring residents' attitude toward sustainable tourism: Development of sustainable tourism attitude scale. Journal of Travel Research, 43(4), 380-394.

Cooke, K. (1982). Guidelines for socially appropriate tourism development in British Columbia. Journal of Travel Research, 21(1), 22-28

Dan Tri (2014). Quán cà phê từ chối phục vụ khách Trung Quốc. Retrieved October 2018 
https://dantri.com.vn/kinh-doanh/quan-ca-phe-tu-choi-phuc-vu-khach-trung-quoc$\underline{1400555715 . h t m}$

Dickinson, J. E., \& Dickinson, J. A. (2006). Local transport and SR: Challenging the assumptions for sustainable tourism. Journal of Sustainable Tourism, 14(2), 192-208.

Dickinson, J. E., \& Robbins, D. (2008). Representations of tourism transport problems in a rural destination. Tourism Management, 29(6), 1110-1121.

Dickinson, J. E., Robbins, D., Filimonau, V., Hares, A., \& Mika, M. (2013). Awareness of tourism impacts on climate change and the implications for travel practice: A Polish perspective. Journal of Travel Research, 52(4), 506-519.

Duveen, G. (2000). Social representations: explorations in social psychology. Cambridge (UK): Polity Press.

Eusébio, C., Vieira, A. L., \& Lima, S. (2018). Place attachment, host-tourist interactions, and residents' attitudes towards tourism development: the case of Boa Vista Island in Cape Verde. Journal of Sustainable Tourism, 26(6), 890-909.

Evans, T. R. (1993). Residents' Perceptions of Tourism in New Zealand Communities. Unpublished, M. Commerce, University of Otago, Dunedin.

Evans-Pritchard, D. (1989). How "they" see "us": Native American images of tourists. Annals of Tourism Research, 16(1), 89-105.

Fedeli, G. (2019). 'Fake news' meets tourism: a proposed research agenda. Annals of Tourism Research. https://doi.org/10.1016/j.annals.2019.02.002.

Fredline, E., \& Faulkner, B. (2000). Host community reactions: A cluster analysis. Annals of Tourism Research, 27(3), 763-784.

Fredline, E., \& Faulkner, B. (2001). Residents' reactions to the staging of major motorsport events within their communities: a cluster analysis. Event Management, 7(2), 103-114.

Giao Duc Viet Nam (2014). Từ chối phục vu người Trung Quốc: Khách sạn không sai cả về lý và tình. Retrieved October 2018 http://giaoduc.net.vn/Kinh-te/Tu-choi-phuc-vu-nguoiTrung-Quoc-Khach-san-khong-sai-ca-ve-ly-va-tinh-post144378.gd

Gibson, H. J., Walker, M., Thapa, B., Kaplanidou, K., Geldenhuys, S., \& Coetzee, W. (2014). Psychic income and social capital among host nation residents: A pre-post analysis of the 2010 FIFA World Cup in South Africa. Tourism Management, 44, 113-122.

Girard, T. C., \& Gartner, W. C. (1993). Second home second view: Host community perceptions. Annals of Tourism Research, 20(4), 685-700.

Gursoy, D., Jurowski, C., \& Uysal, M. (2002). Resident attitudes: A structural modeling approach. Annals of Tourism Research, 29(1), 79-105.

Hair, J.F. JNR, Black, W.C, Babin, B.J \& Anderson, R.E. (2010). Multivariate data analysis: a global perspective. 7th ed. Upper Saddle River: Pearson Prentice Hall.

Hanafiah, M. H., Jamaluddin, M. R., \& Zulkifly, M. I. (2013). Local community attitude and support towards tourism development in Tioman Island, Malaysia. Procedia-Social and Behavioral Sciences, 105, 792-800.

Harrill, R. (2004). Residents' attitudes toward tourism development: A literature review with implications for tourism planning. Journal of Planning Literature, 18(3), 251-266.

Harrill, R., \& Potts, T. D. (2003). Tourism planning in historic districts: Attitudes toward 
tourism development in Charleston. Journal of the American Planning Association, 69(3), 233-244.

Hasani, A., Moghavvemi, S., \& Hamzah, A. (2016). The impact of emotional solidarity on residents' attitude and tourism development. PloS one, 11(6), e0157624.

Haukeland, J. V. (1984). Sociocultural impacts of tourism in Scandinavia: Studies of three host communities. Tourism Management, 5(3), 207-214.

Höijer, B. (2011). Social Representations Theory. Nordicom Review, 32(2), 3-16.

Inbakaran, R., \& Jackson, M. (2006). Resident attitudes inside Victoria's tourism product regions: A cluster analysis. Journal of Hospitality and Tourism Management, 13(01), 5974.

Joffe, H. (2003). Risk: From perception to SR. British Journal of Social Psychology, 42(1), 55-73.

Jurowski, C., Uysal, M., \& Williams, D. R. (1997). A theoretical analysis of host community resident reactions to tourism. Journal of Travel Research, 36(2), 3-11.

Kavaratzis, M. (2004). From city marketing to city branding: Towards a theoretical framework for developing city brands. Place Branding, 1(1), 58-73.

Kemp, E., Childers, C. Y., \& Williams, K. H. (2012). Place branding: Creating self-brand connections and brand advocacy. Journal of Product \& Brand Management, 21(7), 508515.

Kim, W., Jun, H. M., Walker, M., \& Drane, D. (2015). Evaluating the perceived social impacts of hosting large-scale sport tourism events: Scale development and validation. Tourism Management, 48, 21-32.

Lai, P. H., Morrison-Saunders, A., \& Grimstad, S. (2017). Operating small tourism firms in rural destinations: A SR approach to examining how small tourism firms cope with nontourism induced changes. Tourism Management, 58, 164-174.

Lanteigne, M. (2018). China's Soft Power Diplomacy in South Asia: Myth or Reality? BM Jain Lanham, Boulder, CO, New York and London: Lexington Books, 2017 xviii+ 153 pp. ISBN 978-0-7391-9339-6. The China Quarterly, 233, 249-250.

Liu, J. C., \& Var, T. (1986). Resident attitudes toward tourism impacts in Hawaii. Annals of Tourism Research, 13(2), 193-214.

Madrigal, R. (1995). Residents' perceptions and the role of government. Annals of Tourism Research, 22(1), 86-102.

Mason, P., \& Cheyne, J. (2000). Residents' attitudes to proposed tourism development. Annals of Tourism Research, 27(2), 391-411.

Maxwell, J. A. (2005). Qualitative Research Design: An Interactive Approach (2nd Ed. ed.). Thousand Oaks, CA: Sage

McGehee, N. G., \& Andereck, K. L. (2004). Factors predicting rural residents' support of tourism. Journal of Travel Research, 43(2), 131-140.

Merrilees, B., Miller, D., Herington, C., \& Smith, C. (2007). Brand Cairns: an insider (resident) stakeholder perspective. Tourism Analysis, 12(5-6), 5-6.

Moscardo, G. (2009). Tourism and quality of life: Towards a more critical approach. Tourism and Hospitality Research, 9(2), 159-170 
Moscardo, G. (2011). Exploring social representations of tourism planning: Issues for governance. Journal of Sustainable Tourism, 19(4-5), 423-436.

Moscovici S. (1984/2000). The phenomenon of social representations. In: Duveen G. (Ed.). Social representations: explorations in social psychology. Cambridge (UK): Polity Press; (pp. 18-77).

Moscovici, S. (1961). La psychanalyse, son image et son public: étude sur la représentation sociale de la psychanalyse. Presses universitaires de France.

Moscovici, S. (1963). Attitudes and opinions. Annual Review of Psychology, 14, 231-260.

Moscovici, S. (1976). La psychanalyse, son image et son public. Paris: Presses Universitaires de France.

Moscovici, S. (1988) Notes Towards a Description of Social Representations. European Journal of Social Psychology, 18, 211-250.

Moscovici, S. (2001). Social representations. Explorations in Social Psychology. New York University Press.

Moscovici, S., \& Hewstone, M. (1983). Social representations and social explanations: From the "naive" to the "amateur" scientist. Attribution theory: Social and Functional Extensions, 98-125.

Moscovici, S., \& Marková, I. (2001). Ideas and their development: A dialogue between Serge Moscovici and Ivana Marková. In S. Moscovici SR: Explorations in Social Psychology (G. Duveen Ed.; pp. 224-286). New York: New York University Press.

Nantulya, P. (August 2018) Grand Strategy and China's Soft Power Push in Africa. Africa Center for Strategic Studies. Retrieved from https://africacenter.org/spotlight/grandstrategy-and-chinas-soft-power-push-in-africa/

O'Connor, C. (2017). Embodiment and the construction of social knowledge: Towards an integration of embodiment and social representations theory. Journal for the Theory of Social Behaviour, 47(1), 2-24.

Pearce, P. L., Moscardo, G., \& Ross, G. F. (1996). Tourism Community Relationships. Oxford: Pergamon.

Peng. K. (October 2012). How to hard sell China's soft power. China Daily. Retrieved from http://www.chinadaily.com.cn/opinion/2012-10/26/content_15848154.htm.

Perdue, R. R., Long, P. T., \& Allen, L. (1990). Resident support for tourism development. Annals of Tourism Research, 17(4), 586-599.

Presenza, A., \& Sheehan, L. (2013). Planning tourism through sporting events. International Journal of Event and Festival Management, 4(2), 125-139.

Ryan, C., \& Montgomery, D. (1994). The attitudes of Bakewell residents to tourism and issues in community responsive tourism. Tourism Management, 15(5), 358-369.

Schliephack, J., \& Dickinson, J. E. (2017). Tourists' representations of coastal managed realignment as a climate change adaptation strategy. Tourism Management, 59, 182-192.

Sharpley, R. (2014). Host perceptions of tourism: A review of the research. Tourism Management, 42, 37-49.

Sharpley, R. (2018). Tourism, tourists and society (5 $5^{\text {th }}$ Ed.). Routledge: London.

Simpson, P. M., \& Siguaw, J. A. (2008). Destination word of mouth: The role of traveler 
type, residents, and identity salience. Journal of Travel Research, 47(2), 167-182.

Small, K. (2007). Social dimensions of community festivals: an application of factor analysis in the development of the social impact perception (SIP) scale. Event Management, 11(12), 45-55.

Sugiman, T. (1997). A new theoretical perspective of group dynamics. In K. Leung, U. Kim, S. Yamaguchi \& Y. Kashima (Eds.), Progress in Asian Social Psychology, Vol. 1. Singapore: Wiley.

Tan, P.N., Steinbach, M., \& Kumar, V. (2006): Classification: Basic concepts, decision trees, and model evaluation. In Tan PN, Steinbach M, Kumar V (Eds.) Introduction to Data Mining, 1st Ed., Boston: Addison Wesley, pp 145-205.

VNAT (Vietnam National Administration of Tourism). (2018) International visitors to Viet Nam in December and 12 months of 2017. Retrieved October 2018 from http://vietnamtourism.gov.vn/english/index.php/items/12453

Voelklein, C., \& Howarth, C. (2005). A review of controversies about social representations theory: A British debate. Culture \& Psychology, 11(4), 431-454.

VOV (2017). Chinese tourists flooded in the Central [Khách du lịch Trung Quốc tràn ngập miền Trung]. Retrieved April 2019 from https://www.voatiengviet.com/a/khach-du-lichtq-tran-ngap-mien-trung/3760764.html

Vu, K., Nguyen, M., \& Ruwitch, J. (July 2018). China warns citizens in Vietnam after protest over Economic Zones. Reuters. Retrieved from https://www.reuters.com/article/usvietnam-protests/china-warns-citizens-in-vietnam-after-protests-over-economic-zonesidUSKBN1J70NS/

Wagner, W., Duveen, G., Farr, R., Jovchelovitch, S., Lorenzi-Cioldi, F., Marková, I., \& Rose, D. (1999). Theory and method of SR. Asian Journal of Social Psychology, 2(1), 95-125.

Wagner, W., Valencia, J., \& Elejabarrieta, F. (1996). Relevance, discourse and the 'hot' stable core SR-A structural analysis of word associations. British Journal of Social Psychology, 35(3), 331-351.

Ward, C., \& Berno, T. (2011). Beyond social exchange theory: Attitudes toward tourists. Annals of Tourism Research, 38(4), 1556-1569.

Wassler P. \& Hung K. (2017, April). Conceptualizing residents' destination brand ambassador behavior. In INVTUR 2017 Conference Proceedings (pp. 1-13), Aveiro, Portugal.

Wassler, P., Schuckert, M., Hung, K., \& Petrick, J. F. (2018). You're welcome? Hong Kong's attitude towards the Individual Visit Scheme. International Journal of Tourism Research. 637-649.

Williams, J., \& Lawson, R. (2001). Community issues and resident opinions of tourism. Annals of Tourism Research, 28(2), 269-290.

Woosnam, K. M. (2012). Using emotional solidarity to explain residents' attitudes about tourism and tourism development. Journal of Travel Research, 51(3), 315-327.

Woosnam, K. M., \& Aleshinloye, K. D. (2018). Residents' emotional solidarity with tourists: Explaining perceived impacts of a cultural heritage festival. Journal of Hospitality \& Tourism Research, 42(4), 587-605.

Woosnam, K. M., \& Norman, W. C. (2010). Measuring residents' emotional solidarity with tourists: Scale development of Durkheim's theoretical constructs. Journal of Travel 
Research, 49(3), 365-380.

Woosnam, K. M., Norman, W. C., \& Ying, T. (2009). Exploring the theoretical framework of emotional solidarity between residents and tourists. Journal of Travel Research, 48(2), 245-258.

Yuksel, F., Bramwell, B., \& Yuksel, A. (1999). Stakeholder interviews and tourism planning at Pamukkale, Turkey. Tourism Management, 20(3), 351-360.

Zhang, J., Inbakaran, R. J., \& Jackson, M. S. (2006). Understanding community attitudes towards tourism and host-Guest interaction in the urban-rural border region. Tourism Geographies, 8(2), 182-204.

Zhou, Y. (2010). Resident perceptions toward the impacts of the Macao Grand Prix. Journal of Convention \& Event Tourism,11(2), 138-153.

Zhou, Y. J., \& Ap, J. (2009). Residents' Perceptions towards the Impacts of the Beijing 2008 Olympic Games. Journal of Travel Research, 48(1), 78-91.

Zing.vn (2016). Nhà nghì tù chối khách Trung Quốc vì hộ chiếu in 'lưỡi bò'. Retrieved October 2018 https://news.zing.vn/nha-nghi-tu-choi-khach-trung-quoc-vi-ho-chieu-inluoi-bo-post666601.html 